\title{
Is Cycling an Attractive Transport Solution in a Mediterranean City?
}

\author{
Dimitra Tarasi, Tryfon Daras, and Theocharis Tsoutsos
}

\begin{abstract}
By exploiting the opinion of the society in a Mediterranean city, this paper identifies the mechanisms behind utility cycling and determines the aspects of using the bike in cities for daily commuting. This study focused on the assessment of biking as an alternative mode of transport within a typical Mediterranean city in Crete. Limited road safety is the principal reason that hinders $60 \%$ of respondents from cycling, and $41 \%$ from riding more frequently. The survey results are congruent with this statement, provided a significant difference in the ratios of actual recreational cyclists $(39 \%)$ and those who like to ride for entertainment, but they hesitate $(71 \%)$. In order to quantify this, the attitude of the bikers was grouped in two fact factors influencing: the clothing and the technological one. Based on the opinion of the local society, high priority policies are recommended, such as proper infrastructure, sensitization campaigns, and education programs.
\end{abstract}

Keywords Sustainability - Sustainable transport - Cycling - Urban infrastructure Mobility

\section{Introduction}

Global urbanization is increasing rapidly (22\% during the period 1960-2018) (Worldbank, 2018); in Europe, almost three-quarters lives in cities (Eurostat, 2016); it is estimated by 2050 that $68 \%$ of the worldwide population to be located in cities (UN DESA, 2019).

Nevertheless, as cities are escalating, managing them becomes constantly more complicated, while concurrently, the quality of life deteriorates (Tsitoura et al., 2014;

D. Tarasi · T. Tsoutsos $(\varangle)$

Renewable and Sustainable Energy Systems Lab, School of Chemical and Environmental Engineering, Technical University of Crete, Chania, Greece

e-mail: theocharis.tsoutsos@enveng.tuc.gr

T. Daras

Stochastic Models of Tumor Growth Laboratory, School of Chemical and Environmental Engineering, Technical University of Crete, Chania, Greece

e-mail: tryfon@science.tuc.gr 
Tsoutsos, 2018). The speed and sheer scale of the urban transformation presents formidable challenges to the modern world, with mobility being one of them. On the other hand, congestion in metropolis contributes not only to losses in the economic dimension but also to an increase in urban environmental pollution (Bharadwaj et al., 2017).

Urban transport has multidimensional (environmental, economic, social) implications (Purvis et al., 2018). So, as sustainable urban transport is gaining prominence, several articles highlight bike as a sustainable solution to some of the above problems that modern cities have. Cycling is eco-friendlier, healthier due to physical activity, requires limited public space, and is more economically attractive (Pucher \& Buehler, 2017).

Nonetheless, how much is cycling a sustainable mode of transport within the city? Although there have been several studies concerning cycling, analyzing the best infrastructures to promote cycling, or examining the health and economic benefits (Doorley et al., 2020; Van Duppen \& Spierings, 2013), the current literature is relatively limited on its sustainability as an alternative mode of transport within the Mediterranean cities. This paper seeks to address the question mentioned above, identify the mechanisms behind utility cycling, and determine the aspects of using the bike in Mediterranean cities for daily commuting. In parallel, the main aim of the current study is the analysis of the cultural facet of city cycling, given that the transition to urban sustainability is strongly linked with it. In a nutshell, this study set out to assess the current situation regarding city cycling and ascertain the potential barriers that prevent a Mediterranean city from being bike-friendly.

\section{State of the Art}

Concerning the health benefits, cycling can protect from chronic diseases (Buehler et al., 2011; WHO, 2004); 6-10\% of the deaths for which non-communicable diseases are responsible (2.5-4.0 million annually) due to physical inactivity (Biddle, 2016; Kohl et al., 2012). Moreover, it plays a role in decreasing cancer risk, with a 40$50 \%$ reduction for colon cancer, a 20-30\% reduction for breast cancer, and a $20 \%$ reduction for ovarian and lung cancer (Rebecchi et al., 2016). According to statistics, only a small share (17\%) of the Greek population spends at least $2.5 \mathrm{~h} /$ week of leisure time doing physical activities, such as cycling (Eurostat, 2017); this is the minimum level of physical activity recommended by the World Health Organization for adults (WHO, 2010).

On the other hand, the environmental advantages of cycling cannot be ignored. In 2014, the transport sector was responsible for $21 \%$ of global $\mathrm{CO}_{2}$ emissions (Worldbank, 2014). On the contrary, the bike can contribute significantly to the mitigation of climate change. More specifically, a study concluded that a dramatic increase (about $20 \%$ ) in urban cycling worldwide could decrease $\mathrm{CO}_{2}$ emissions from transportation by $11 \%$ (Mason et al., 2015). Additionally, cycling reduces air pollution, as well as water and soil contamination, alongside having a smaller manufacturing footprint. 
Furthermore, replacing car by bike can achieve economic benefits both for the citizens and for the society. Cycling contributes to more livable cities via less congestion, better air quality, less noise, and more space for people. These features, in turn, create attractive metropolis, with increased tourism revenue from eco-tourists, which is crucial for the Mediterranean cities. In parallel, it saves money as it reduces expenditure on health, on vehicles, on-road surfaces, on expensive, and polluting fossil fuels (Neun \& Haubold, 2016). Besides that, cycling-related industries create a series of new jobs, and investments in cycling support local shops (Dekoster and Schollaert 1999).

Last but not least, the social benefits of cycling are regarded to be equally essential. The bike provides increased mobility to low-rate social groups, such as low-income earners and youngsters (Ji et al., 2017). An additional convenience that is worth noting is the fact that it enables people to interact socially, and this enhances a sense of community. Similarly, shared cycling and pedestrian infrastructure, such as improved paths, also create benefits for pedestrians and people bringing justice between population groups. A study shows that specific infrastructure and behavioral change encourage to cycle from home to work regularly (Xu \& Chow, 2020).

Notwithstanding, several cities in Europe demonstrate the feasibility of the reduction in the use of private cars. Nonetheless, despite the multi-faceted merits of cycling, many cities continue to privilege vehicles by prioritizing car-centric policies and planning (Mayers \& Glover, 2019). Most Greek cities fall into the abovementioned rule, due to the urban development which lacks infrastructure; regardless the fact that there has been a boost in cyclists the last decade, as a result of the recent financial crisis, Greece is not generally recognized as a country where bike culture prevails, despite the favorable weather conditions.

It has been conclusively shown that roads which guarantee a high level of safety encourage residents to use bikes.

\subsection{Study Area}

According to the latest census, the permanent population of the Municipality of Chania amounts to 108.642 inhabitants (our area of interest was the municipal units of Chania downtown, Akrotiri and Souda with 61,275 inhabitants (ELSTAT, 2011)). The climate of the region is the subtropical Mediterranean, with sunny, dry summers, and very mild, rainy winters. Snow and frost are rare near the coast, and during the period between April and October, clear-sky weather is almost a common feature. Concerning the topography, the city's center can be described as mild, with minimum elevations. In contrast, high-altitude differences of over $200 \mathrm{~m}$ can be observed to the Akrotiri Peninsula, which extends northeast of the city. It is noteworthy to point out that the Technical University of Crete, a major part of the city's life, is located in the peninsula mentioned above. Last but not least, regardless of the lack of cycling network, in 2015, a municipal bike-sharing system was officially launched with four stations within the city's center boundaries. 


\subsection{Research Methodology}

Cycling in the city of Chania has been scarcely investigated from the transportation point of view; most studies focus on the potential construction of cycle lanes within the city or the near suburbs. Within this framework, parameters such as the volume of cyclists-bike owners, the frequency and reasons for cycling trips, the way that citizens commute to their work or the city's center and their notion regarding the bike use as an alternative transport mode have not to be taken into consideration. That is to say, there is no prior research concerning the topics mentioned above, neither information that depicts the present situation of the city.

There were contacts with: (a) European Cyclists' Federation; (b) Confederation of the European Bicycle Industry; (c) Greece's major bike manufacturing companies which could provide the annual sales of the industry, alongside with the market's tendency; (d) local bike dealers and shops with the view to form an opinion respecting the local market and the proportion of the population that cycle; and (e) Chania's amateur cycling group Podilatreis (in Greek: bike lovers), which was considered of utmost importance, taking into account the fact that they are active the last decade and they could conceivably provide valuable information.

Under the lack of essential cycling raw data, and in order to gain insight into the current state regarding cycling in the city of Chania, a survey has been conducted. The four-stage work was implemented with the support of a structured questionnaire (Bechhofer \& Paterson, 2000; McNeill, 1990), and tested through a pilot study:

1. the development of a structured questionnaire;

2. its distribution;

3. data gathering/recording; and

4. data analysis.

The questionnaire included both close-ended and open-ended questions (Bradburn et al., 2004) and grouped into the following five sections:

1. personal data;

2. general information;

3. transportation within the city;

4. cycling in the city and infrastructures; and

5. driving conduct.

It was regarded as vital to include the behavioral aspect in the survey, as it is partially unexplored and obscure yet of great significance. Commonly, cycling research is mainly oriented toward quantitative data collection, and calls little, if any, attention to the qualitative features of the subject. Moreover, participants were allowed to state their viewpoint freely on the issue, exchange their ideas and make suggestions.

The research carried out during the period December 2018-January 2019 was addressed to adult citizens of Chania and it was distributed both online, as it ensures the reaching out to a broader population, and in the paper. The digital format of 
the questionnaire was created with the tool "Google forms." Notably, social media platforms enhanced further promotion of the survey. In all cases, participants' consent was obtained, and since the questionnaire was anonymous, there was no need to abide by the General Data Protection Regulation (GDPR). The collected data were analyzed using SPSS v.20 (Apostolakis et al., 2009; Green et al., 2000). Besides, they were tested for face-value validity and reliability (Cronbach, 1951).

\section{Results}

\subsection{General Information}

The random sample consisted of 272 citizens, weighted w.r.t. the percentage of current/projected (by the future sales) bike owners (53.7\% men and $46.3 \%$ women). This analogy between men and women is estimated as the rationale for local bikers based on the (empirical) experience of the researchers. Of the study population, $74.3 \%$ owns a bike, and among those who do not, only one-quarter responded that it is quite possible to purchase one soon. There is a dependence relation between the sex of a survey participant and the fact that he/she is a bike owner (men are more often bike owners, 87.7-58.7\% for women, $\mathrm{x}^{2}=29.640$, sig $=0.000$ ) (Table 1).

Regarding the participants' age, the majority, 36.4\%, is middle-aged (35-44 years old). There is also a dependence relation between the age of a participant and the fact that he/she is a bike owner (adults of age 45-54 are more frequent owners, $90 \%$ $\mathrm{x}^{2}=16.712$, sig $\left.=0.000\right)($ Table 2$)$.

Concerning the utility reasons, there was no clear trend observed, given the fact that there was an absolute equilibrium between transportation and physical activity ( $47.5 \%$ and $47.9 \%$ respectively). In other words, for one out of two participants, the cited purpose for cycling is either traveling or exercising. On the other hand, a figure of $38.9 \%$ declared themselves as recreational cyclists.

There is a statistically significant difference in the way men and women use the bike: men usually use the bike for transportation (55.2-38.5\% for women), physical

Table 1 Bike ownership w.r.t. sex

\begin{tabular}{|c|c|c|c|c|c|}
\hline & & & \multicolumn{2}{|c|}{ Bike owner } & \multirow[t]{2}{*}{ Total } \\
\hline & & & Yes & No & \\
\hline \multirow[t]{4}{*}{ Sex } & \multirow[t]{2}{*}{ Man } & Count & 128 & 18 & 146 \\
\hline & & $\%$ within sex & 87.7 & 12.3 & 100.0 \\
\hline & \multirow[t]{2}{*}{ Woman } & Count & 74 & 52 & 126 \\
\hline & & $\%$ within sex & 58.7 & 41.3 & 100.0 \\
\hline \multirow{2}{*}{\multicolumn{2}{|c|}{ Total }} & Count & 202 & 70 & 272 \\
\hline & & $\%$ within sex & 74.3 & 25.7 & 100.0 \\
\hline
\end{tabular}


Table 2 Bike ownership w.r.t. age

\begin{tabular}{|c|c|c|c|c|c|}
\hline & & & Bike & & Total \\
\hline & & & Yes & No & \\
\hline Age & $18-24$ & Count & 23 & 20 & 43 \\
\hline & & $\%$ within age & 53.5 & 46.5 & 100.0 \\
\hline & $25-34$ & Count & 43 & 12 & 55 \\
\hline & & $\%$ within age & 78.2 & 21.8 & 100.0 \\
\hline & $35-44$ & Count & 73 & 26 & 99 \\
\hline & & $\%$ within age & 73.7 & 26.3 & 100.0 \\
\hline & $45-54$ & Count & 45 & 5 & 50 \\
\hline & & $\%$ within age & 90.0 & 10.0 & 100.0 \\
\hline & Over 55 & Count & 18 & 7 & 25 \\
\hline & & $\%$ within age & 72.0 & 28.0 & 100.0 \\
\hline Total & & Count & 202 & 70 & 272 \\
\hline & & $\%$ within age & 74.3 & 25.7 & 100.0 \\
\hline
\end{tabular}

activity (60.1-33.6\%), recreation (46.9-29.5\%) and women tend not to use the bike at all (45.9-18.9 for men).

When questioned about the frequency of riding, $29.5 \%$ claimed to cycle 4-7 times/week, while $18.8 \%$ mentioned using the bike less, that is to say, 1-3 times/week. It is worth noting that almost three out of ten participants do not cycle at all, even though they are bike owners. The rest of the sample, $24.1 \%$, alleged occasional use of 1-3 times/month or less. Men (38.5\%) and adults of age range 45-54 (42.9\%) are more frequent bike users (Fig. 1).

Notwithstanding, $70.2 \%$ of the individuals declared not to cycle as frequently as they would like $(81.8 \%$ of women to $60.4 \%$ of men, difference statistically significant, $\mathrm{x}^{2}=14.393$, sig $\left.=0.000\right)$.

Concerning the causes that hinder the more frequent use, the lack of infrastructure prevails with a striking $70 \%$. Nevertheless, safety reasons do not fall far behind, as they prohibit $41.4 \%$ of cyclists from riding more often. Third on the list was encountered the weather conditions since $32.7 \%$ referred to them as the main reason for infrequent use (Table 3).

The results can also be verified by employing (through exploratory factor analysis/ e.f.a.) of two latent variables/factors. One factor loads the variables "Tiring," "Time," and "Other Means" (named Factor1) and a second one loads the variables "Not Safe" and "Infrastructure" (named Factor2) (here KMO $=0.531$, for Bartlett's test $\mathrm{p}<$ 0.05 and factors explain $53.56 \%$ of the common variable variance) (Fig. 2). Thus, we have to keep in mind the non-existence of proper infrastructure relates (strongly) with safety concerns.

Interestingly enough, the data yielded by this study provide convincing evidence that the lack of bike lanes and safety reasons are again responsible for not using a bike. More specifically, one out of three subjects do not cycle, due to the absence of 


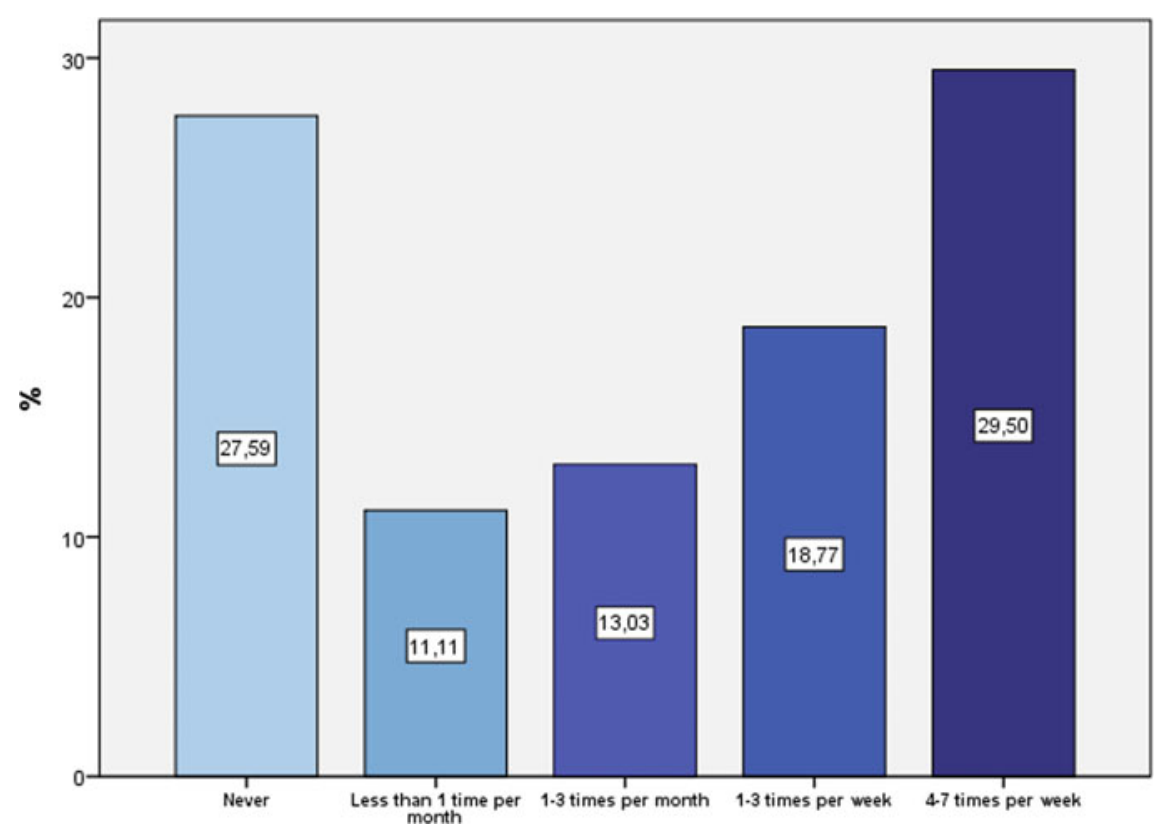

Fig. 1 Frequency of the bike use

Table 3 Reasons for not frequent use

\begin{tabular}{l|l|l|l}
\hline \multicolumn{2}{c|}{} & Responses & \multirow{2}{*}{$\%$ of cases } \\
\cline { 3 - 4 } \multicolumn{2}{c|}{} & $\mathrm{N}$ & \\
\hline \multirow{3}{*}{$\begin{array}{l}\text { Reasons for no } \\
\text { frequent use }\end{array}$} & No infrastructure & 154 & 70.0 \\
\cline { 2 - 4 } & Not safe & 91 & 41.4 \\
\cline { 2 - 4 } & Not a bike owner & 37 & 16.8 \\
\cline { 2 - 4 } & Weather & 72 & 32.7 \\
\cline { 2 - 4 } & Other means & 29 & 13.2 \\
\cline { 2 - 4 } & Other & 14 & 6.4 \\
\cline { 2 - 4 } & Tiring & 13 & 5.9 \\
\hline
\end{tabular}

a bike network within the city in one hand $(63.2 \%)$, and safety reasons in the other $(56.9 \%)$.

Regarding the major benefits of cycling, the available data indicate that almost half of the sample $(47.4 \%)$ evaluated the easy transportation as an outstanding advantage. In contrast, for $30.4 \%$ of the participants, the fact that bike is an environmentally friendly means of transport with zero emissions of $\mathrm{CO}_{2}$ is of utmost importance. Finally, there is the smallest proportion of individuals (11.9\%), who underlined the fact that it is a low-cost way of traveling. 


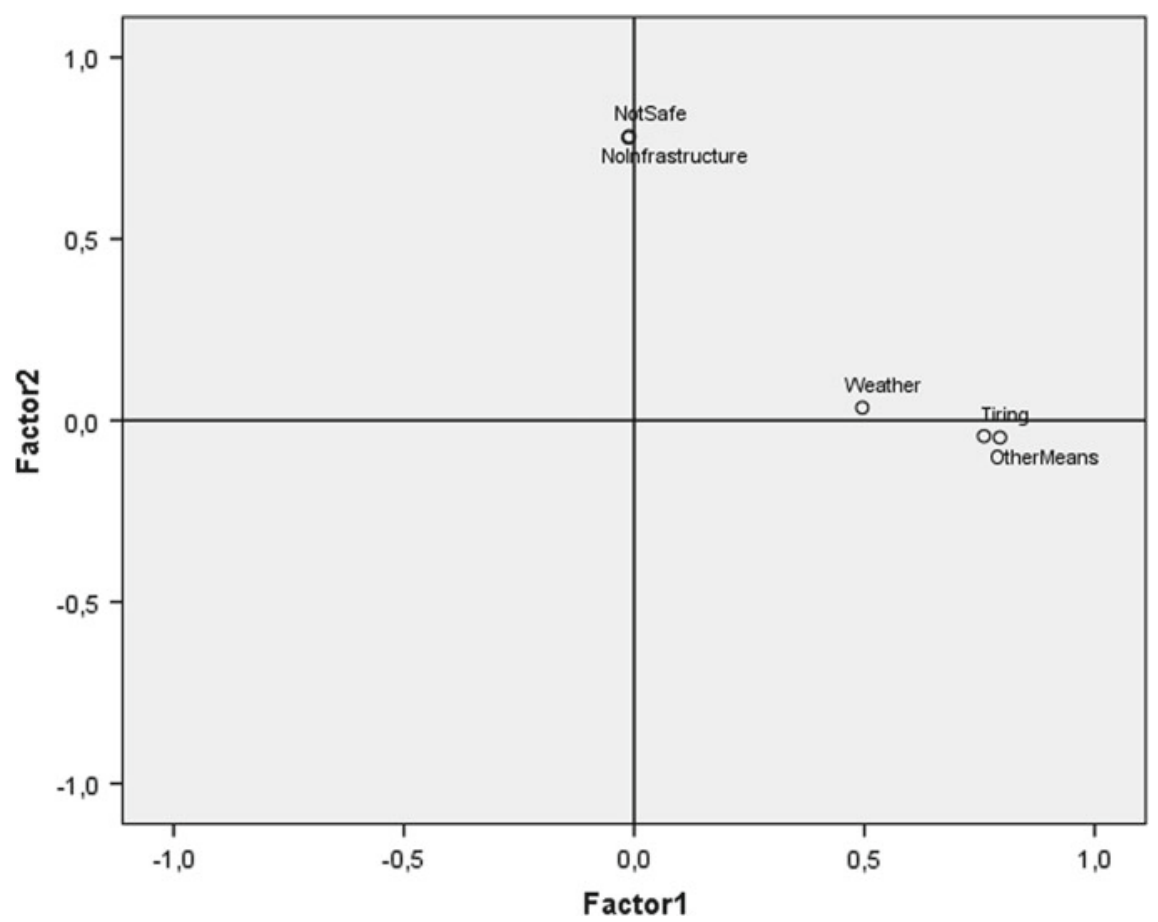

Fig. 2 Graphical representation of variables in Factors' space

There is a difference, statistically significant $\left(\mathrm{x}^{2}=13.137\right.$, sig. $\left.=0.004\right)$, between men and women on which is the most crucial advantage of bike riding. Women considered as the main reason the fact that there is no environmental pollution (39.2$22.8 \%$ for men), in contrast with men who think its main advantage is that it is an easy transportation mean (57.2-36\% for women) (Table 4).

Table 4 Advantage of bike use w.r.t. sex

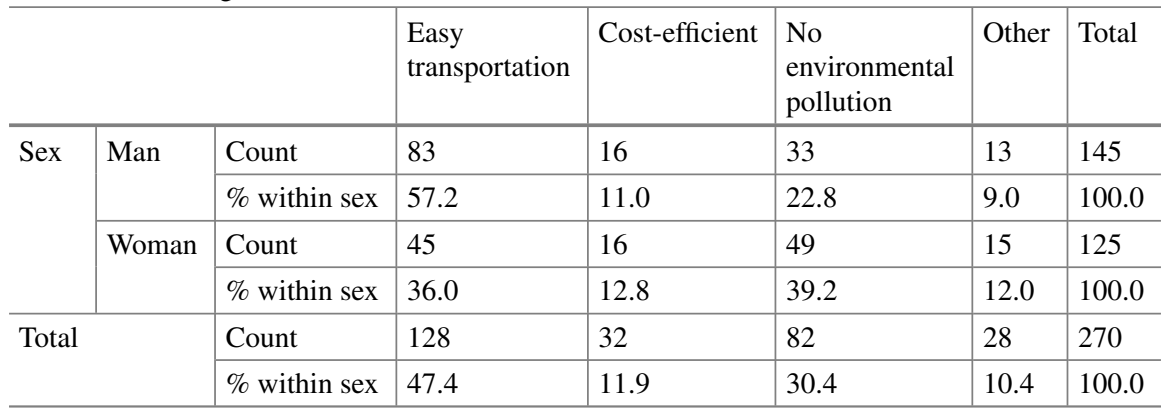




\subsection{Transportation Within the City}

When a hypothetical question was posed to the subjects, in respect of the potential use of the bike, the majority of those surveyed (71.9\%) indicated that they would cycle for recreation. In contrast, an almost equal proportion (70\%) suggested that it would be useful for commuting to the work or the university. Besides, one out of two persons asserted that he/she would ride a bike to go shopping. In other words, it would be used as a mode of transport.

Men and women use the bike, inside the city, in different ways. Men mainly use the bike for commuting to work (64.1-47.2\% for women), and women, on the other hand, use it mostly for shopping (64.8-49\% for men). Additionally, concerning age, the majority of those in the age group 18-24 use it for commuting to university (40.5\%). These differences are statistically significant (level of significance $\mathrm{a}=0.05$ ).

In another scenario, slightly over half of the study population $(54.8 \%)$ would definitely choose the bike over another means of transport for traveling within the city. The same standpoint, but with an insignificant reservation, shared $22.6 \%$ of the respondents.

Men, to a greater extent than women, would use the bike over any other means of transportation (65.5-42.4\% for women, difference statistically significant, $\mathrm{x}^{2}=$ 15.132 , sig $=0.004)$. The prevailing reasons for opting for a different means of transport instead of bike coincided with the previously mentioned ones. More precisely, the findings demonstrate that, for $71.6 \%$ of the total, the key factor was the lack of infrastructure, followed by $50.6 \%$ who highlighted the safety parameter. Lastly, the adverse weather conditions were the underlying argument in favor of choosing other modes of transportation for $37 \%$ of the study population (Table 5).

Moreover, these results can be verified, in a similar manner as in paragraph 4.1, with the use also of the same two factors.

Women feel less safe, when cycling, in contrast with men $\left(59.3-41 \%\right.$ for men, $\mathrm{x}^{2}$ $=5.489$, sig $=0.019$ ).

Table 5 No preference frequencies

\begin{tabular}{l|l|l}
\hline \multirow{2}{*}{} & Responses & \% of cases \\
\cline { 2 - 3 } & $\mathrm{N}$ & \\
\hline Not a bike owner & 30 & 18.5 \\
\hline Not safe & 82 & 50.6 \\
\hline Tiring & 12 & 7.4 \\
\hline Weather conditions & 60 & 37.0 \\
\hline Infrastructure & 116 & 71.6 \\
\hline Time & 20 & 12.3 \\
\hline Other means & 16 & 9.9 \\
\hline Other & 5 & 3.1 \\
\hline
\end{tabular}


Also, members of the sample of age group 18-24 (51.7\%) consider less, when cycling, the absence of infrastructure (in comparison with the other age groups, they think in a percentage of more than $80 \%$ the infrastructure).

Drawing from the survey results, it is evident that infrastructure and safety were the two features of paramount importance for the participants and the key drivers of their viewpoint regarding the adoption of cycling as an alternative way of transportation. Even though indirectly it had already been underpinned the fact that the sample does not feel safe to cycle, a direct question in which they had to evaluate the level of security while cycling, accentuated it even more. To be more specific, a significant proportion, $43.7 \%$ of the people surveyed, admitted to feeling totally unsafe, while another $25.9 \%$ and $23.7 \%$ reported a high and moderate feeling of insecurity, respectively. Furthermore, women feel less safe when cycling (57.6-31.7\% for men), and in contrast, bike owners feel safer $(63.2-37.1 \%$ for non-bike owners).

The safety issue also emerged when the sample was requested to assess the feeling of being exposed to the possibility of theft or harassment as cyclists, given that for the majority $(72.8 \%)$, this risk is high.

Nonetheless, which are the predominant challenges that citizens are experiencing when they are traveling within the city? According to $74.3 \%$, the number one adversity they are facing is road safety. Consequently, this issue arose again, and it became crystal clear that it is a subject of great importance for the inhabitants. A high rate of the respondents $(63.6 \%)$ described traffic congestion as a significant problem, while air contamination and noise pollution were mentioned by the $32.2 \%$ and $26.4 \%$ of the sample, respectively. Last but not least, a figure of $26.4 \%$ declared that the principal impediment in their everyday commuting is the delay due to congested roads (Fig. 3).

Also, using e.f.a., the main challenges/problems can be expressed using two factors. The first factor includes the variables "Traffic," "Delays" and we could probably name it "Traffic Problems"; on the second factor, the variables "Pollution" and "Sound Pollution" are being loaded, and we can call it "Pollution Problems" (here $\mathrm{KMO}=0.601$, Bartlett's test $\mathrm{p}<0.05$ and factors explain $67.85 \%$ of the common variable variance). The factor loadings (using Varimax rotation) of the variables can be seen in Eqs. 1-2:

$$
\begin{aligned}
\text { Traffic Problems }= & 0.694 * \text { Traffic }+0.515 * \text { Delays } \\
& -0.194 * \text { Pollution }+0.58 * \text { Sound Pollution }
\end{aligned}
$$

$$
\begin{aligned}
\text { Pollution Problems }= & -0.203 * \text { Traffic }+0.077 * \text { Delays } \\
& -0.688 * \text { Pollution }+0.520 * \text { Sound Pollution }
\end{aligned}
$$

So, except for safety, policy measures have to be taken by the state/municipality for traffic and pollution problems. 


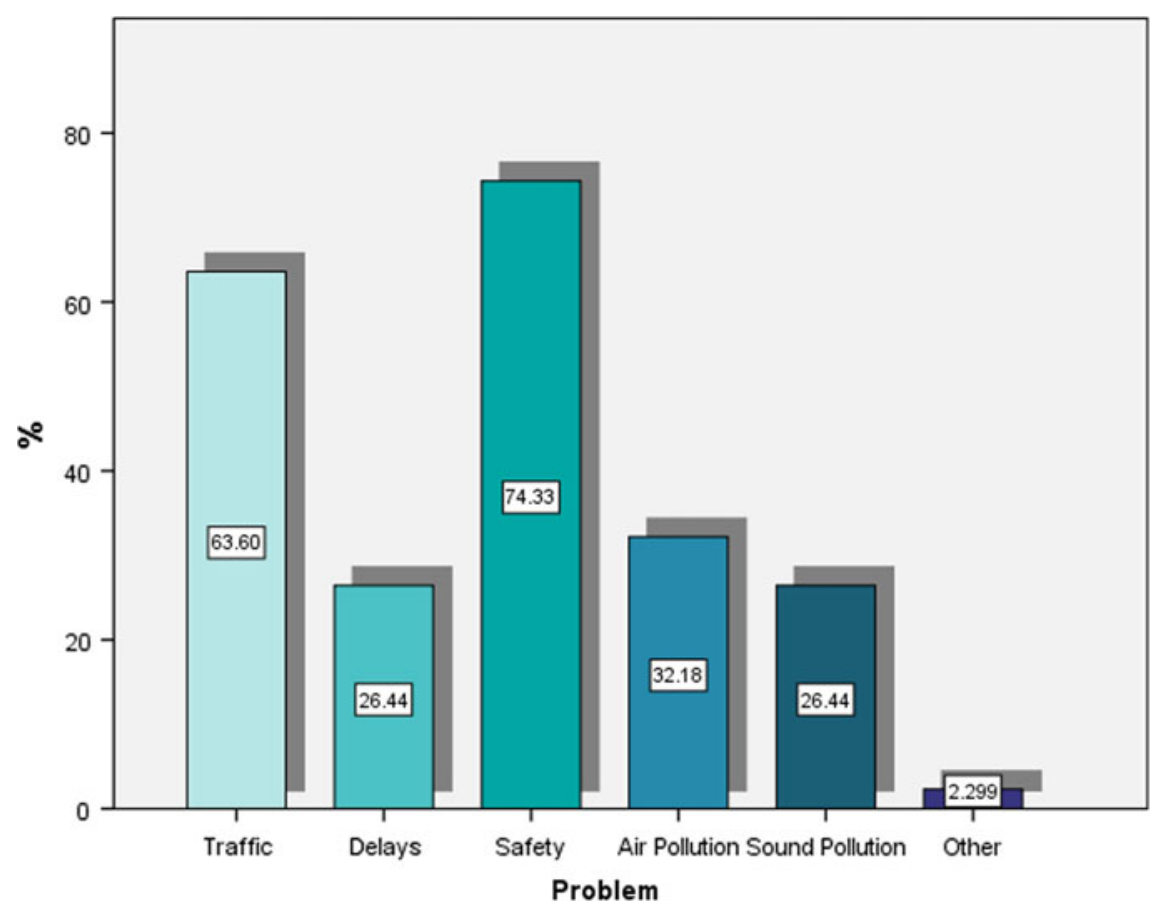

Fig. 3 Problems moving around the city

\subsection{Cycling in the City and Infrastructures}

Another interesting point is the citizens' opinion and reaction concerning the construction of bike lanes. What would happen if there was a complete bike network within the city? Would they opt for cycling? The results of the survey concerning this matter appear to be undeniable, provided that an overwhelming $90 \%$ claimed that, in case of infrastructure, they would use a bike. Hardly a $2.6 \%$ was opposed to this idea, while the remaining 7.4\% stated: "I don't know." Bike owners are more willing to use these type of networks (96-72.1\% for non-bike owners, $\mathrm{x}^{2}=33.182$, $\operatorname{sig}=0.000)$.

Furthermore, a similar attitude was observed, respecting the use of a bike in the case of infrastructure. When the subjects were questioned if they would cycle for commuting to their workplace or the university, an astonishing $79.2 \%$ reported "Yes," in contrast with a $12.6 \%$ who opposed to it, while the remaining $8.2 \%$ appeared indecisive.

Similarly, impressive is the proportion of those who are in favor of the construction of cycle lanes. $97 \%$ of the participants would support such an initiative, while $88.4 \%$ of them consider the existence of bike parking facilities essential. 


\subsection{Driving Conduct}

An additional section of the questionnaire aimed to evaluate cyclists' driving conduct. Do they abide by the traffic rules and regulations? The results obtained from the study were revealing in several ways. First, almost $60 \%$ obeys the rules, while a great proportion of roughly $37.3 \%$ stated that they follow the existing driving regulations but not always (Fig. 4). Bike owners seem to obey the traffic rules more often (60.8$54 \%$ for non-bike owners, $\left.x^{2}=9.396, \mathrm{sig}=0.009\right)$. Secondly, a striking observation that emerged from the data was the fact that four out of ten cyclists never wear a helmet while riding, and only one-third of them (32.9\%) wears it regularly. Men and bike owners wear a helmet more regularly $(43.1 \%$ for men to $18.6 \%$ for women and $6.5 \%$ for bike owners to $13.5 \%$ for non-bike owners).

Furthermore, it is interesting to note that $23.3 \%$ of the cyclists have their headphones on every so often when riding, and an almost equivalent percentage (22\%) do not take them off. Also, only one out of four bike riders use proper cycling clothing, and nearly eight out of ten $(84.3 \%)$ wear at least light reflectors. The percentage is

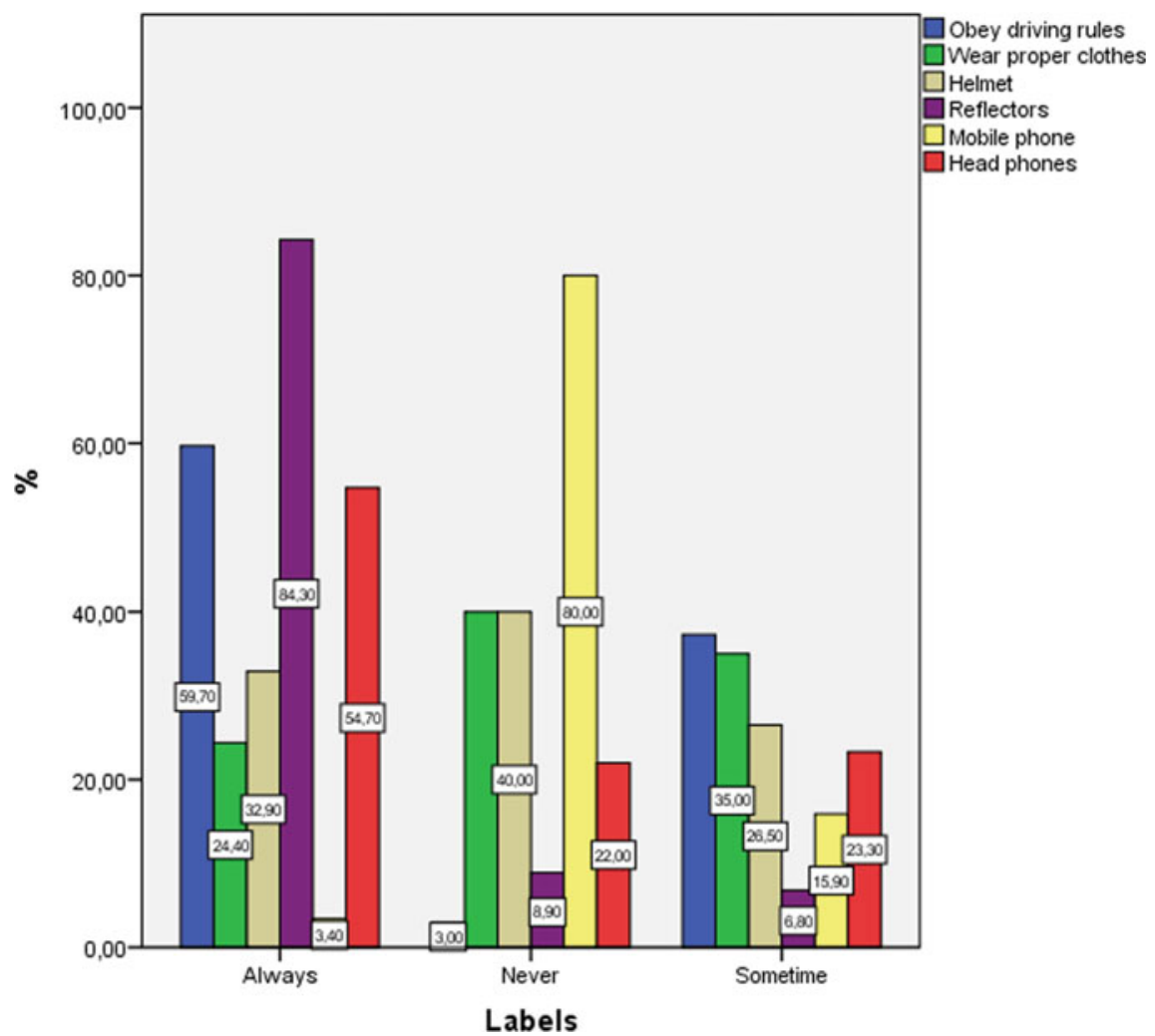

Fig. 4 Overall driving behavior 
even higher for bike owners, $87.9 \%$ to $64.9 \%$ for non-bike owners $\left(x^{2}=14.629\right.$, sig $=0.001$ ).

As a final point, the use of a mobile phone while riding is undoubtedly a significant issue, given that this practice underlies a high risk. The findings demonstrate that the majority $(80.7 \%)$ of the study population does not use it when riding, and only the minority $(15.9 \%)$ uses it occasionally.

By using exploratory factor analysis the driving behavior data processed (i.e., variables "Proper Clothing Use," "Helmet Use," "Night Light Reflectors Use," "Headphones Use," "Mobile Use") in order to find out latent factors justifying the data (not measured, driving behavior, variables).

Choosing principal component analysis and orthogonal Varimax rotation, and since all KMO values for individual variables were above 0.05, Kaiser-Meyer-Olkin measure was also $>0.50$ (adequacy of the sample), Bartlett's test of sphericity $\mathrm{p}<$ 0.05 (no multicollinearity problems), and an eigenvalue cut-off of 1.0 (also confirmed by the scree plot), we ended up with two factors explaining $58.17 \%$ of the common variance.

The variables "Proper Clothing Use," "Helmet Use" are being loaded to the first factor, through the model of Eq. 3:

$$
\begin{aligned}
\text { Clothing Behavior }= & 0.905 * \text { Proper CLothing }+0.905 * \text { Helmet Use }+ \\
& +0.162 * \text { Night Light Reflectors Use }+0.134 * \text { Mobile Use } \\
& -0.113 * \text { Headphones Use }
\end{aligned}
$$

and we can probably call this factor Clothing Behavior. Furthermore, the variables "Night Light Reflectors Use," "Headphones Use," and "Mobile Use" are being loaded to the second factor, through Eq. 4,

$$
\begin{aligned}
\text { Technology Behavior }= & 0.012 * \text { Proper Clothing Use }+0.034 * \text { Helmet Use }+ \\
& +0.681 * \text { Night Light Reflectors Use } \\
& +0.611 * \text { Mobile Use }-0.613 * \text { Headphones Use }
\end{aligned}
$$

and we can probably call this factor Technology Behavior. The higher the individual scores w.r.t. the variables/factors, the better the load to the factor (for the reliability of the two new factors: Cronbach's alpha > 0.750).

So the (explanation of psychology behind) driving behavior could be split into two parts, the clothing equipment on the one hand and the technical equipment on the other and a (possible) future policy could be based on these two different parts. Also, using t-tests and ANOVA, there is a (statistically) significant difference in Clothing Behavior w.r.t. sex, age, and bike ownership. Men, individuals of age 34-45, and bike owners score higher w.r.t. this factor. Also, there is a (statistically) significant difference in Technology Behavior w.r.t. bike ownership.

Finally, it is worth noting that 47 respondents declared their personal perspective regarding the subject, and made beneficial recommendations and comments. 


\section{Discussion and Conclusions}

Under the lack of bike lanes, the city of Chania can be identified as car-centric, as a consequence of traffic congestion, poor air quality, and noise pollution (as we have also seen in the factor analysis). The survey results are congruent with this statement, provided that a significant difference in the ratios of actual recreational cyclists was observed (39\%) and those who would like to ride for entertainment, but hesitate (71\%). Nevertheless, according to some participants' comments, car-centrism is not only preventing citizens from cycling, but it is also a cultural problem that will take much time to change.

A recurrent theme in the study which emerged, in most cases indirectly, yet of utmost importance, was a sense among participants of none or limited road safety. This is the principal reason that hinders $60 \%$ of respondents from cycling, and $41 \%$ from riding more frequently. Authors of studies in this field point to the fact that roads which do not guarantee a high level of safety discourage residents from using bikes (Van Holle et al., 2014). Enlightening is the comment of a participant: "After the incidents of serious and fatal injuries to cyclists over the past few years, I confess that fear prevents me from getting back on the bike even though I had bought a brand new bike."

Nonetheless, the insecurity mentioned above stems from the lack of appropriate infrastructure in one hand and poor driving conduct on the other (both verified by the exploratory factor analysis). According to the findings, there is a significant and undeniable relationship between the absence of bike lanes, and none or limited use of the bike. As one individual stated: "No cycle lanes, no safety." A similar philosophy was observed for $63 \%$ of the respondents, who reported a compelling reason for not cycling the lack of infrastructure. Moreover, an even higher proportion (70\%) not only would cycle more if it was less risky, but also would opt for a bike instead of other means of transport.

The significance of infrastructures and the positive impact that would have on the mobility behavior of the citizens has been highlighted already by several researchers (Majumdar \& Mitra, 2018). In this study, the results of the survey demonstrated that, if the better infrastructure of bike lanes was available, the outstanding $90 \%$ of the citizens would cycle. Among them, $79 \%$ would commute to work or the university by bike. Secondly, the participants' statements left no room for doubt. In other words, infrastructures would set a clear trend toward the change in travel habits and the adoption of cycling.

An additional crucial issue that emerged through this study was cyclists' poor driving skills. There were a plethora of comments which referred to this topic and accentuated the necessity of immediate improvement.

A further interesting finding of this research that it should be taken into account is the fact that the inhabitants appeared to be almost unanimously (97\%) in favor of the construction of cycle lanes. Moreover, a common belief among them was the strong link between appropriate facilities and the promotion of cycling. As one individual put it: "Only infrastructure can push citizens to use the bike." This finding 
corroborates the ideas of Cervero et al. (2013), who suggested that building safe, secure, and well-designed bike infrastructure increases the number of cyclists and encourages cycling.

One rather disappointing finding was the fact that former cyclists have abandoned riding their bikes as a consequence of always feeling conscious of their safety while cycling. Without any doubt, the lack of infrastructure, in tandem with the poor driving conduct, contributes significantly to this sensation.

Overall, these results suggest that it is imperative to emphasize the construction of the appropriate infrastructure in one hand, and on the cultivation of cycling culture in the other. Alongside, it is vital to ameliorating the citizens' driving behavior.

Despite the advances toward a sustainable city, obviously, the late financial crisis that resulted in critical modifications in the everyday life of citizens, including travel behavior, Chania remains a car-centric city. The lack of prioritization for cycling is a cultural barrier, which has proven difficult to change. These changes require long periods, during which the population develops new mobility behavior. Thus, it will be a long time until the bike outweighs the vehicles regarding transportation within the city.

In order to achieve the desired mindset and meet the constant need for more sustainable mobility, the implementation of specific policies aiming to the cultivation of cycling culture is indispensable. More precisely, the use of "soft interventions," such as awareness campaigns and events, has proven to be remarkably effective. Particular attention should be given to the young generation, given that it is of paramount importance to inculcate in them the philosophy of sustainable and environmentally friendly transportation. For that reason, educational programs should be incorporated in schools' curriculum, in hand with experiential ones, because experiential learning has astonishing results. Nevertheless, cycle training for adults, who are either inexperienced or wish to regain their riding confidence, could be an additional measure. Concerning the promotion of city cycling, a series of initiatives, in particular, subvention for bike purchasing, incentives for cycling to work, and expansion of the bike-sharing project, could have as well a positive effect (Table 6).

Turning now to the future work that could be performed in this field, more extensive research could establish more robust evidence. Aside from that, taking into serious consideration the fact that studies on the behavioral change regarding cycling in the city are lacking, further research on this topic is required. Another critical question for future studies to resolve is whether people perceive the long-term benefits of limiting the use of the private car. In a broader level, research is also needed in order to determine the reasons behind the poor driving conduct. 
Table 6 Recommended policies to encourage cycling in the city of Chania

\begin{tabular}{|c|c|c|c|}
\hline Policy measures & Target audience & Actor & Time horizon \\
\hline \multicolumn{4}{|l|}{ Change of the mindset } \\
\hline $\begin{array}{l}\text { Behavioral change educational } \\
\text { programs }\end{array}$ & $\begin{array}{l}\text { Children } \\
\text { Students }\end{array}$ & $\begin{array}{l}\text { Municipality } \\
\text { Schools } \\
\text { Academia }\end{array}$ & Short term \\
\hline Experiential learning programs & $\begin{array}{l}\text { Children } \\
\text { Students }\end{array}$ & $\begin{array}{l}\text { Municipality } \\
\text { Bicycle clubs } \\
\text { Parent associations }\end{array}$ & Short term \\
\hline Safety campaigns & Women & $\begin{array}{l}\text { Municipality } \\
\text { Schools } \\
\text { Academia }\end{array}$ & Short term \\
\hline Environmental campaigns & Men & $\begin{array}{l}\text { Municipality } \\
\text { Schools } \\
\text { Academia }\end{array}$ & Short term \\
\hline \multicolumn{4}{|l|}{ Infrastructure } \\
\hline $\begin{array}{l}\text { Improvement of the quality and } \\
\text { extension of infrastructure }\end{array}$ & General Public & $\begin{array}{l}\text { Municipality } \\
\text { State }\end{array}$ & Medium-Long term \\
\hline $\begin{array}{l}\text { Traffic problems' monitoring } \\
\text { and improvement }\end{array}$ & $\begin{array}{l}\text { Municipality } \\
\text { General public }\end{array}$ & $\begin{array}{l}\text { Municipality/ } \\
\text { State }\end{array}$ & Short-Long term \\
\hline Regulation monitoring & General public & $\begin{array}{l}\text { Police } \\
\text { Municipality }\end{array}$ & Short term \\
\hline \multicolumn{4}{|l|}{ Incentives } \\
\hline Incentives for cycling to work & General public & \begin{tabular}{|l} 
State \\
Employers
\end{tabular} & Short term \\
\hline $\begin{array}{l}\text { Subvention for bicycle } \\
\text { purchasing }\end{array}$ & General public & $\begin{array}{l}\text { State } \\
\text { Bicycle dealers }\end{array}$ & Short term \\
\hline
\end{tabular}

\section{References}

Apostolakis, I., Daras, T., \& Stamouli, M. A. (2009). Exercises in applied statistics in health sector (Vol. 2). Papazisis Publishers (in Greek).

Bechhofer, F., \& Paterson, L. (2000). Media reviews. Principles of research design in the social sciences. Routledge Taylor \& Francis Group.

Bharadwaj, S., Ballare, S., Rohit, \& Chandel, M. (2017). Impact of congestion on greenhouse gas emissions for road transport in Mumbai metropolitan region. Transportation Research Procedia, $25,3538-3551$.

Biddle, S. (2016). Physical activity and mental health: Evidence is growing. World Psychiatry, 15(2), 176-177.

Bradburn, N., Sudman, S., \& Wansink, B. (2004). Asking questions. The definitive guide to questionnaire design for market research, political polls, and social and health questionnaires (Revised). Jossey-Bass-John Wiley \& Sons Inc.

Buehler, R., Pucher, J., Merom, D., \& Bauman, A. (2011). Active travel in Germany and the U.S. American Journal of Preventive Medicine, 41(3), 241-250.

Cervero, R., Caldwell, B., \& Cuellar, J. (2013). Bike-and-ride: build it and they will come. Journal of Public Transportation, 16(4), 83-105. 
Cronbach, L. (1951). Coefficient alpha and the internal structure of tests. Psychometrika, 16(3), 297-334.

Dekoster, R., \& Schollaert U. (1999). Cycling: the way ahead for towns and cities. European Commission, Luxembourg.

Doorley, R., Pakrashi, V., Szeto, W. Y., \& Ghosh, B. (2020). Designing cycle networks to maximize health, environmental, and travel time impacts: An optimization-based approach. International Journal of Sustainable Transportation, 14(5), 361-374.

ELSTAT. (2011). Census 2011. Retrieved August 20, 2019, from http://www.statistics.gr/2011-cen sus-pop-hous.

Eurostat. (2016). Share of urban and rural populations, 1950-2050 $\left(^{1}\right)(\%$ of total population) Cities16.png-Statistics explained. Retrieved August 20, 2019, from https://ec.europa.eu/eur ostat/statistics-explained/index.php?title=File:Share_of_urban_and_rural_populations,_1950\% E2\%80\%932050_(\%C2\%B9)_(\%25_of_total_population)_Cities16.png.

Eurostat. (2017). How much do Europeans exercise?. Retrieved August 20, 2019, from https://ec. europa.eu/eurostat/web/products-eurostat-news/-/DDN-20170302-1.

Green, S., Salkind, N., \& Akey, T. (2000). Using SPSS for windows. Analyzing and understanding data (2nd ed.). Practice Hall.

Ji, Y., Fan, Y., Ermagun, A., Cao, X., Wang, W., \& Das, K. (2017). Public bicycle as a feeder mode to rail transit in China: The role of gender, age, income, trip purpose, and bicycle theft experience. International Journal of Sustainable Transportation, 11, 308-317.

Kohl, H., Craig, C., Lambert, E., Inoue, S., Alkandari, J., Leetongin, G., \& Kahlmeier, S. (2012). The pandemic of physical inactivity: Global action for public health. The Lancet, 380(9838), 294-305.

Majumdar, B., \& Mitra, S. (2018). Analysis of bicycle route-related improvement strategies for two Indian cities using a stated preference survey. Transport Policy, 63, 176-188.

Mason, J., Fulton, L., \& McDonald, Z. (2015). A global high shift cycling scenario: The potential for dramatically increasing bicycle and E-bike use in cities around the world, with estimated energy, $\mathrm{CO}_{2}$, and cost impacts. Institute for Transportation \& Development Policy and University of California, Davis, USA.

Mayers, R., \& Glover, T. (2019). Whose lane is it anyway? The experience of cycling in a Mid-sized City. Leisure Sciences, 1-18.

McNeill, P. (1990). Research methods (2nd ed.). Routledge.

Neun, M., \& Haubold, H. (2016). The EU cycling economy-arguments for an integrated EU cycling policy. European Cyclists' Federation, Brussels.

Pucher, J., \& Buehler, R. (2017). Cycling towards a more sustainable transport future. Transport Reviews, 37(6), 689-694.

Purvis, B., Mao, Y., \& Robinson, D. (2018). Three pillars of sustainability: In search of conceptual origins. Sustainability Science, 14(3), 681-695.

Rebecchi, A., Boati, L., Oppio, A., Buffoli, M., \& Capolongo, S. (2016). Measuring the expected increase in cycling in the city of Milan and evaluating the positive effects on the population's health status: A community-based urban planning experience. Annali Di Igiene, 28(6), 381-391.

Tsitoura, M., Tsoutsos, T., \& Daras, T. (2014). Evaluation of comfort conditions in urban open spaces. Application in the island of Crete. Energy Conversion and Management, 86, 250-258.

Tsoutsos, T. (2018). Sustainable energy and mobility as drivers for the economic growth in the Mediterranean islands. Renewable Energy and Sustainable Development, 4(2), 56.

UN DESA. United Nations Department of Economic and Social Affairs. (2019). 68\% of the world population projected to live in urban areas by 2050, says UN. UN DESA. United Nations Department of Economic and Social Affairs. Retrieved August 20, 2019, from https://www.un.org/dev elopment/desa/en/news/population/2018-revision-of-world-urbanization-prospects.html.

Van Duppen, J., \& Spierings, B. (2013). Retracing trajectories: The embodied experience of cycling, urban sensescapes and the commute between 'neighbourhood' and 'city' in Utrecht, NL. Journal of Transport Geography, 30, 234-243. 
Van Holle, V., Van Cauwenberg, J., Deforche, B., Goubert, L., Maes, L., Nasar, J., Van de Weghe, N., Salmon, J., \& De Bourdeaudhuij, I. (2014). Environmental invitingness for transport-related cycling in middle-aged adults: A proof of concept study using photographs. Transportation Research Part A: Policy and Practice, 69, 432-446.

WHO. (2004). The global strategy on diet, physical activity and health (DPAS). Retrieved August 20, 2019, from https://www.who.int/nmh/wha/59/dpas/en/.

WHO. (2010). Global recommendations on physical activity for health. Retrieved August 20, 2019, from https://www.who.int/dietphysicalactivity/factsheet_recommendations/en/.

Worldbank (2014). CO2 emissions from transport (\% of total fuel combustion). Data. Retrieved August 20, 2019, from https://data.worldbank.org/indicator/EN.CO2.TRAN.ZS.

Worldbank. (2018). Urban population (\% of total population). Data. Retrieved August 20, 2019, from https://data.worldbank.org/indicator/SP.URB.TOTL.IN.ZS.

Xu, S. J., \& Chow, J. Y. Y. (2020) A longitudinal study of bike infrastructure impact on bikesharing system performance in New York City. International Journal of Sustainable Transportation.

Open Access This chapter is licensed under the terms of the Creative Commons Attribution 4.0 International License (http://creativecommons.org/licenses/by/4.0/), which permits use, sharing, adaptation, distribution and reproduction in any medium or format, as long as you give appropriate credit to the original author(s) and the source, provide a link to the Creative Commons license and indicate if changes were made.

The images or other third party material in this chapter are included in the chapter's Creative Commons license, unless indicated otherwise in a credit line to the material. If material is not included in the chapter's Creative Commons license and your intended use is not permitted by statutory regulation or exceeds the permitted use, you will need to obtain permission directly from the copyright holder. 